\title{
Traffic characteristics and bridge loading in South Africa
}

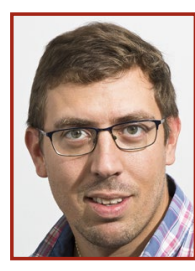

DR ROMAN LENNER (PE) is a senior lecturer at Stellenbosch University in the Department of Civil Engineering. His main research interests include structural reliability, bridge loading, target reliability and assessment of existing structures. He holds a Dr.-Ing from the University of German Armed Forces in Munich.

Contact details:

Department of Civil Engineering

Private Bag X1

Matieland 7602

South Africa

T: +27218089572

E: rlenner@sun.ac.za

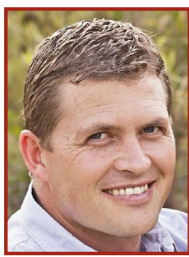

GERHARD DE WET (Pr Eng) founded Static

Motion (Pty) Ltd in 2016 after having worked for AECOM SA (known as BKS until 2012) for 16 years. His special fields of interest are overloading management, weigh-in-motion (WIM), electronic traffic monitoring and data quality management. He has been working on the overloading management projects of the four toll concessions surrounding Gauteng (N1 North, Bakwena, TRAC and N3TC) for most of his career. He completed his Master's Degree on Post-calibration and Quality Management of WIM data in 2010.

\section{Contact details:}

Static Motion (Pty) Ltd

PO Box 40167

Faerie Glen

Pretoria 0043

T: +27828534674

E: gerharddw@staticmotion.co.za

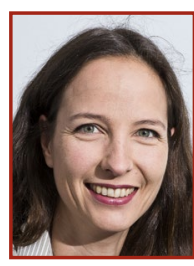

DR CELESTEVILJOEN (Pr Eng, MSAICE) is a researcher on structural risk and reliability at Stellenbosch University. She is a member of SABS TC98/02, the convenor of the working group developing SANS 10100-3, a member of the working group for the revision of ISO 13824 and a member of the international Joint Committee on Structural Safety.

Contact details:

Department of Civil Engineering

Private Bag X1

Matieland 7602

$\mathrm{T}:+27218084947$

E.cbarnardo@sun.acza

\author{
R Lenner, D P G de Wet, C Viljoen
}

The loading model of the Technical Manual for Highways (TMH-7) published for bridge design in South Africa is in need of revision and simplification. The frequency of heavy vehicle loads has increased and the current application of the loading model is unnecessarily cumbersome. This paper aims to compare the heavy vehicle traffic loading of South Africa and Europe. A comparison of global internal bridge forces under the NA loading of TMH-7 and LM1 loading of Eurocode provides an indication of how current South African provision relates to the ones adopted in Europe. Above all, the traffic characteristics in South Africa are investigated in comparison to data used in development of LM1.

LM1 loading generally results in higher internal forces when compared to TMH-7 loading. A direct adoption would thus imply more expensive bridges across South Africa without substantiation, considering the satisfactory past performance of existing structures. More importantly, the gross vehicle weights observed in South Africa are higher than those used for the development of LM1, indicating that the current TMH-7 distributed loading may be too low. Axle loads and their variability in South Africa are somewhat less than in Europe, so local design effects are less of a concern. It is apparent that further urgent work is required to establish a load model that reflects the current heavy vehicle traffic and predicts appropriate characteristic vertical loads.

\section{INTRODUCTION}

As some of the structural standards in South Africa are becoming outdated, or in some cases are entirely missing, it becomes necessary to either develop new codes or adapt foreign ones. This has been extensively discussed by the engineering community, including authorities, practising professionals and academics. As a result, portions of Eurocodes (EN) have been implemented in South Africa. This is illustrated by means of the revised South African National Standard (SANS) 10160: Basis of structural design and actions for buildings and industrial structures (SANS 2011).

The code for bridge design in South Africa is the Technical Manual for Highways 7 (TMH-7) (CSRA 1981) which was essentially developed in the 1970s. It has been performing well, but there are some concerns regarding its present status since it is partially based on an outdated British standard. A suitable course of action is still wide open for debate. It has been recognised that the current version of the bridge code needs to be revised; however, there is no consensus about which actions should take place. The most urgent aspect is regarded as the revision of the traffic loading, as discussed at the South African Institution of Civil Engineering (SAICE) Eurocode Summit (SAICE 2008). The main problems with the current load formulation resort in the complicated concept of aggregate lane length, variable loading intensity, partial loading of influence surfaces and the concept of variable lane width (CSRA 1991). The currently prescribed model leads to an overly complicated application, and thus brings an unnecessary burden to the practising engineer. The complexity of analysis also leads in many cases to errors in estimation of the resulting design forces.

The aim of this paper is to critically compare actual traffic in South Africa to the traffic data used to develop the loading model of EN 1991-2: Actions on structures, Traffic loads on bridges (EN 2010), in order to provide some guidance for possible remedial actions regarding the current TMH-7 load model (CSRA 1981) and to comment on the possibility of adopting (or adapting) a simpler loading model, such as the one given in EN 1991-2.

\section{COMPARISON}

As a start, a brief comparison of the expected internal forces as a result of codified loading models needs to be provided to establish a benchmark for further discussion.

Investigations of design effects corresponding to the currently used NA and NB load models in TMH-7 in both serviceability and ultimate limit states are necessary. This 
includes global internal forces - shear and moments (bending and torsion). The results may be largely influenced by the number of notional lanes as dictated by the deck width. It is therefore necessary to consider a variable bridge width when calculating global internal forces due to traffic. A special consideration must be further devoted to culverts and retaining walls, which is outside the scope of this paper.

In this contribution, as an example, a single-span beam bridge with variable deck width and span length was utilised and loaded with characteristic loads. Two load models were considered - LM1 (EN 1991-2), as shown in Figure 1, and NA loading (TMH7), respectively. The EN 1991-2 was chosen simply due to the predominant alignment of newly developed/adapted SANS codes with the Eurocodes.

\section{EN 1991-2}

The bridge loading within the Eurocode suite of standards is governed by the EN 1991-2: Actions on structures, Traffic loads on bridges (EN 2010). This standard covers the loading by both road and rail; however, with the emphasis on road bridges. The vertical load model for road bridges was essentially developed in the 1990s by evaluating traffic records, specifically 1986 Auxerre data (Sedlacek et al 2008), running simulations and extrapolating calculated load effects for different scenarios to include most design situations. As a result, EN 1991-2 presents four loading models in its Section 4.3: LM1 for general and local verifications, LM2 for short members, LM3 for special heavy vehicles and LM4 for crowd loading in transient design situations. The main model, LM1, is used for comparison in this contribution. The model utilises a fixed $3 \mathrm{~m}$ notional lane width with defined concentrated loads in the form of a tandem axle $\left(\alpha Q_{i}\right)$ and a uniform loading $\left(\alpha q_{i}\right)$ for each lane (see Figure 1 ), where the $\alpha$ is an adjustment factor defined in the National Annex, typically taken as unity. For the design, deck width is therefore divided into respective notional lanes and loaded accordingly to the lane number in order to produce the most adverse effect.

\section{TMH-7}

Vertical traffic loading is governed by Section 2.6 in Part 2 of TMH-7 (CSRA 1981). The live loading due to traffic is essentially divided into Normal Loading (NA), Abnormal Loading (NB) and Super Loading (NC), whereas NC may be omitted on certain roads. The standard traffic loading consists of NA loading and 36 units of NB load. This paper mainly concentrates on the comparison of the NA loading, which
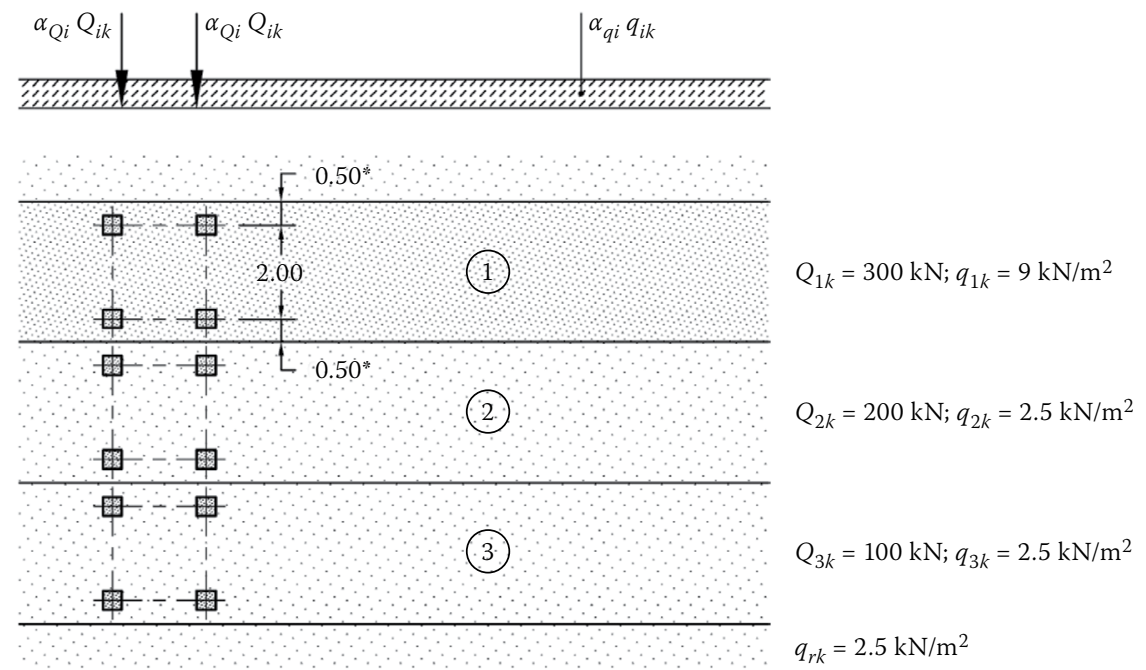

Figure 1: LM1 Model in EN1991-2 [5]

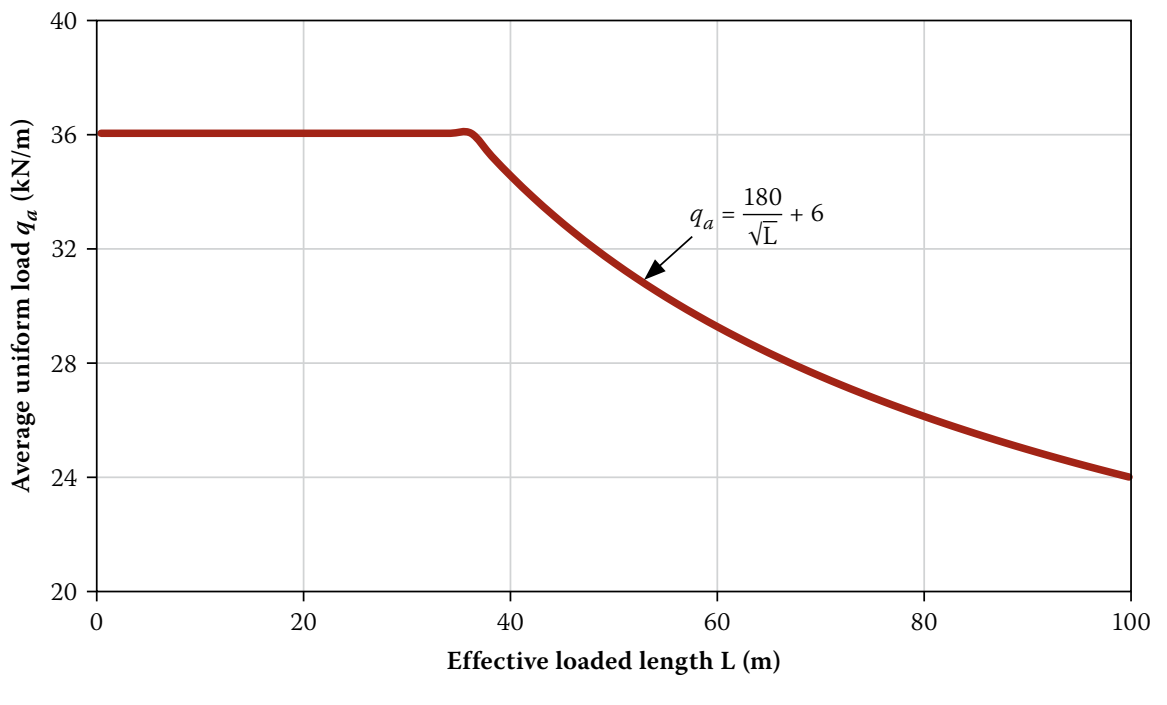

Figure 2: Average uniform distributed load intensity according to TMH-7

utilises a floating lane notional lane width. The deck width is divided by an integer depending on the overall curb-to-curb distance (consult Table 2.6 in THM-7 Part 2). The specific issue with the NA loading is the variable intensity of the uniformly distributed load $q_{a}$ according to the total aggregate loaded length applied on the whole or parts of any notional lane contributing to the most adverse effect (refer to Figure 2). In addition, a knife-edge load of $144 / \sqrt{n} \mathrm{kN}$ is applied at each lane, where $n$ is the lane number.

\section{INTERNAL FORCES}

A simple Euler beam model was used for the analysis, and therefore only global longitudinal internal forces were obtained by means of hand calculations. The LM1 model was taken with $\alpha=1.0$, which implies the standard loading. A standard lane notational lane width is $3 \mathrm{~m}$.
NA loading was factored with $k=1.1$ to compensate for a partial loading of influence lines for the static system, as prescribed by TMH7-Part 2. The limits for deck width and span length are arbitrarily chosen in this exercise to illustrate the resulting difference between the codes; note that LM1 is calibrated for up to $200 \mathrm{~m}$ span lengths (EN 2010). No partial factors are applied, indicating a comparison of service loads.

The difference in the resulting internal action is calculated according to:

$\Delta=-1+\frac{X_{\mathrm{NA}}}{X_{\mathrm{LM} 1}}$

where $\Delta$ corresponds to the difference fraction (negative means internal forces due to LM1 are higher compared to NA), $X_{\mathrm{NA}}$ is the load effect due to THM-7 NA loading, and $X_{\mathrm{LM} 1}$ is the load effect due to EN 1991-2 LM1 loading. Figures 3(a)-(c) show the 
results with the difference factor plotted on the vertical axis.

It is clear that the variation of the global internal forces is considerable and largely depends on the span length and the deck width. The deck width is important due to the nature of notional lane definition. NA loading has a floating width to fit the deck, while EN1991-2 requires a 3 m lane. This results in abrupt changes of the total internal forces with increasing deck width. The load effect due to NA tends to be more severe in some regions as additional notational lanes are added. With increasing span lengths the difference fractions clearly reduce. However, the overall trend is for LM1 to deliver higher internal forces. Thus, a direct adoption of EN 1991-2 would imply an increase in safety, but a reduction in economy for South African bridges without any substantiation. It is therefore necessary to investigate the traffic loading and intensity on South African roads, and compare the results to the traffic used in the development of EN 1991-2.

\section{TRAFFIC MEASUREMENT AND DATA}

Weigh-in-Motion (WIM) systems are widely used in South Africa to measure dynamic axle loads at free-flow speeds. The axle loading data is most commonly used in pavement management systems for planning purposes and for timeous scheduling of pavement maintenance actions. They are also used as screeners in conjunction with load control centres for preselection of potentially overloaded vehicles for accurate weighing, and prosecution if necessary. Lastly, they are used for intensive monitoring of overloading on toll concessions, since concession contracts mostly allow for the cost of overloading to be claimed back from the South African National Roads Agency (SANRAL).

Some of the best WIM data in the country has been collected on toll roads over the past 15 years owing to the strong emphasis on data quality for these applications and additional routine scrutiny of data quality. The most commonly used WIM technology on these routes is bending plates that are embedded in the road surface, mostly in the left wheel path only to save cost. Data calibration and quality management procedures on toll concessions use locally developed methods (De Wet 2010) that are endorsed by SANRAL (De Wet 2008). The calibration method and key elements of the quality assessment procedures were incorporated into the new Technical Methods for Highways document that details traffic and axle load monitoring procedures in South Africa, TMH-8 (COTO 2014). (a)

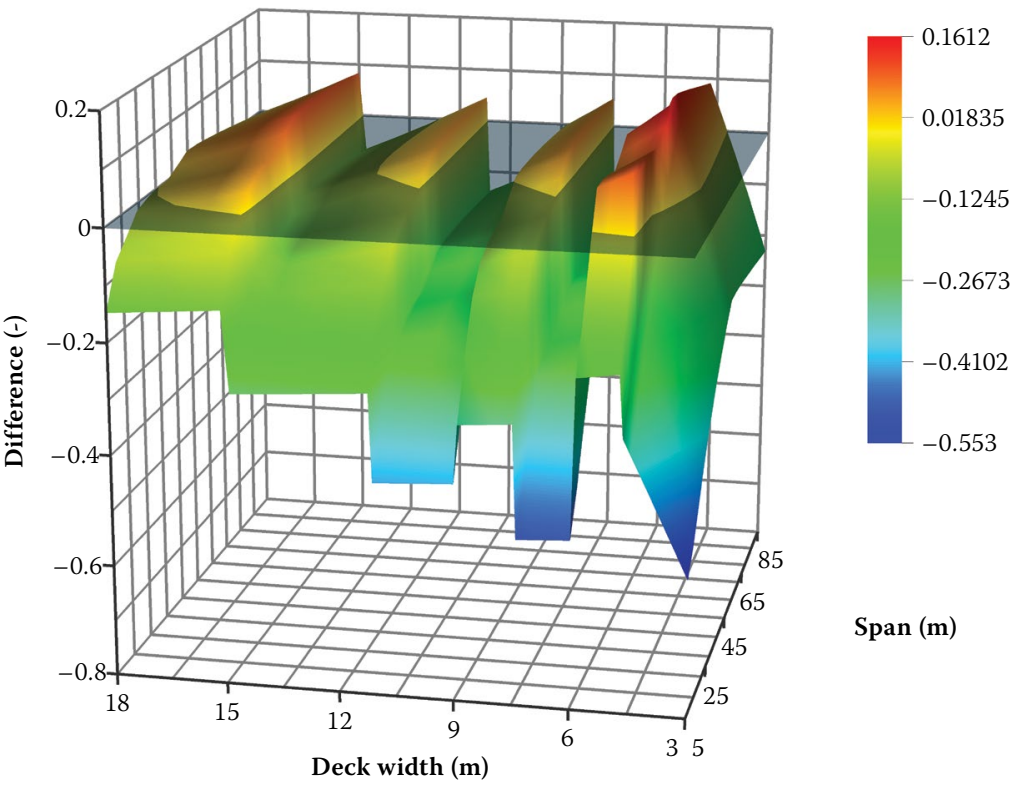

(b)

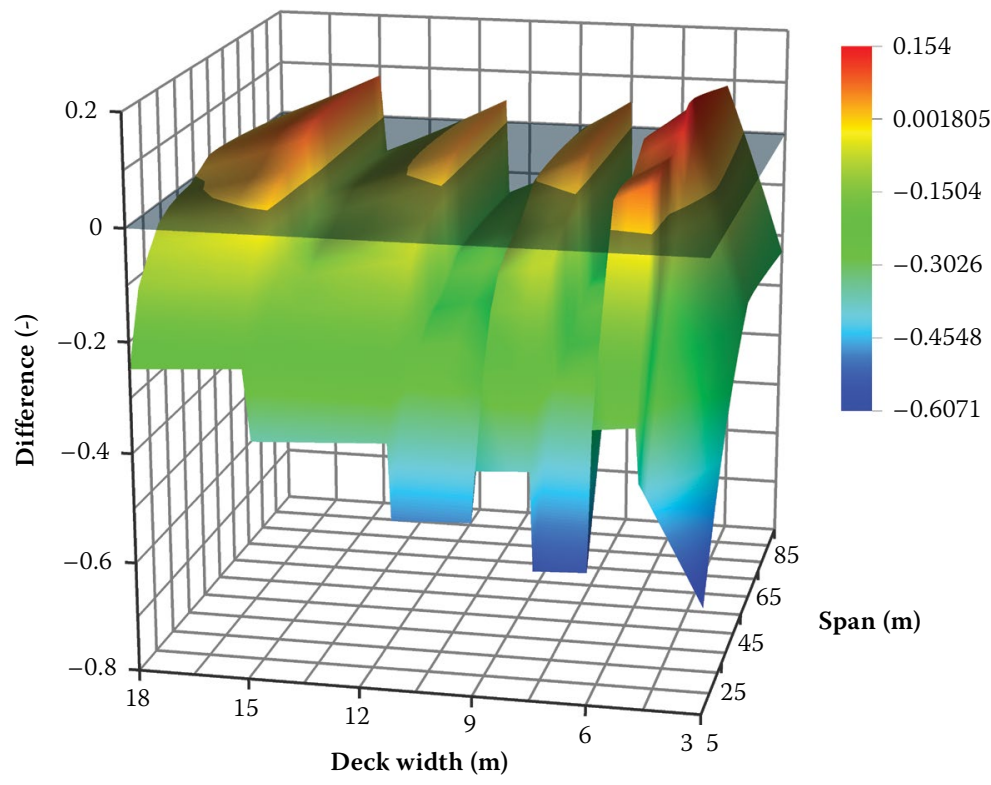

(c)

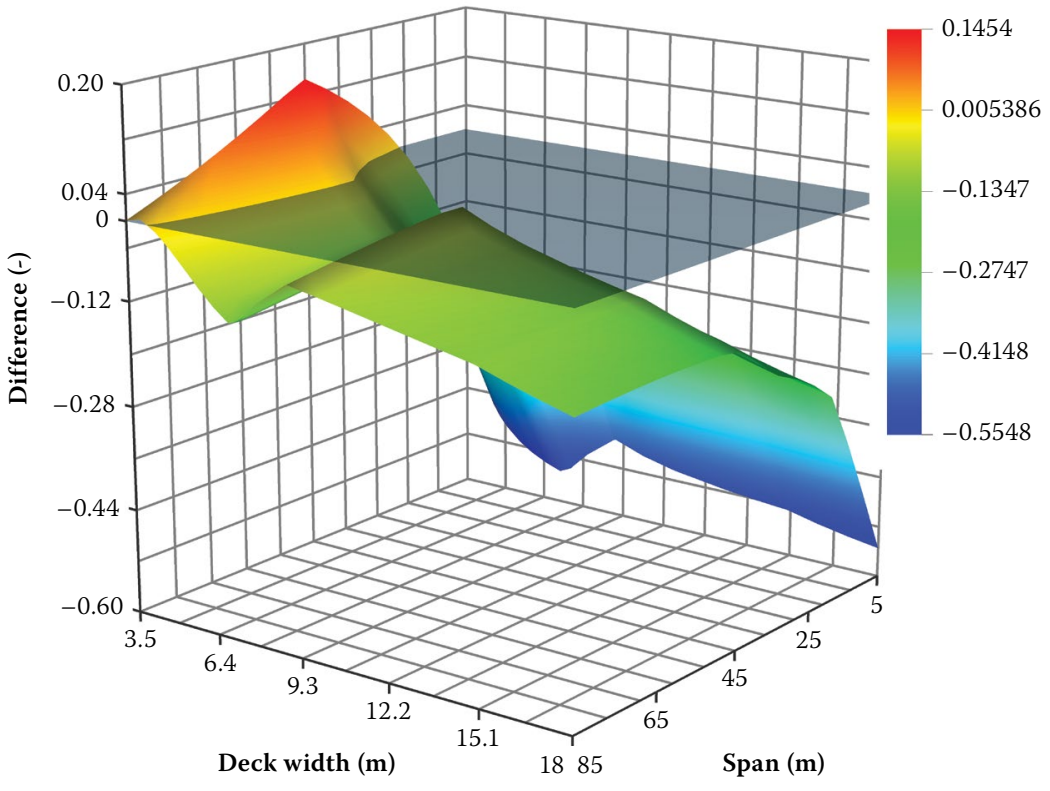

Figure 3: Difference fractions of the internal forces caused by TMH-7 loading vs EN 1991-2 loading for (a) bending moment, (b) shear and (c) torsion 
The latest proposed WIM accuracy requirement in the TMH-3 specification for traffic and WIM monitoring services (COTO 2016) is that typical data collection WIMs in South Africa should measure the Gross Vehicle Mass of $95 \%$ of vehicles accurately to within 10\%. This requirement is still being debated, as an extensive history of WIM performance on the N1 North, N3, N4 East and Bakwena toll routes indicates that good single-sensor WIM stations (measuring in the left wheel path only) typically achieve between $10 \%$ and $15 \%$ accuracy on Gross Vehicle Mass. Screening WIMs with left and right wheel path sensors are generally accurate to within $10 \%$. The above accuracies are aligned with the accuracy requirements for data collection WIMs (Class C15) and screening WIMs (Class B10) depicted in the European COST 323 WIM Standard (COST 2002). Most South African WIMs therefore produce data of internationally acceptable quality, and valuable inference may be made from axle load distributions despite the measurement scatter caused by vehicle dynamics.

In addition to axle loads, WIM traffic data collection systems also enable calculation of headways between vehicles, and produce axle spacing data that allows for detailed classification of vehicles.

New bridge loading models are usually based on measured traffic data, simulations and extrapolation of results for various scenarios in order to produce reliable and conservative loading patterns. In order to produce a suitable pattern for the traffic load model, detailed information from the measured WIM must be obtained to include (Sedlacek et al 2008):
- Frequency distribution of the axle loads

- Frequency distribution of the distances between axles

- Frequency distribution of different types of vehicles

- Frequency distribution of distances between vehicles.

With such data it would be possible to either develop or calibrate a bridge loading model that is truly based on actual traffic intensity. There is inherent variability in the traffic load in terms of geographical position, traffic conditions (road slope, intersections, number of lanes, etc) and time. It is therefore usually necessary to examine numerous WIM stations and obtain patterns that are representative for the whole region where the code should apply.

In this paper WIM data from Auxerre located in France is compared with Roosboom, located on a typical heavy-freight route in South Africa, in order to get an idea of the traffic characteristics on the roads and to guide future intervention steps for the revision of TMH-7.

\section{Auxerre, France}

The background document to EN1991-2: Traffic Loads on Road Bridges (Sedlacek et at 2008) and DIN-Report 101 (Hanswille \& Sedlacek 2007) present the basis of development for the bridge load model in the current Eurocode. More importantly, both documents show the characteristics of original traffic records that were used in the prediction of the loading effects. This essentially comprises a traffic data sample measured in 1986 in Auxerre, France (Sedlacek et al 2008). WIM data was gathered at a number of different locations throughout Europe, but the 1986 Auxerre data record proved to have the highest rate of heavy vehicles and axle loads (Hanswille \& Sedlacek 2007). Figure 4 shows accumulated distributions of gross vehicle weight (GVW) and axle loads (P). In this figure $n_{30}$ is a number of vehicles with GVW above $30 \mathrm{kN}$ and $n_{10}$ represents a number of axle loads above $10 \mathrm{kN}$. The rate of heavy vehicles and axles is an important characteristic when developing a loading model. The data used for the evaluation was recorded over an extended period of time, ranging up to 800 hours. More information on the different measuring stations and vehicle distribution is provided in (Hanswille \& Sedlacek 2007), again highlighting the large percentage of heavy vehicles present at the Auxerre measuring site. Auxerre traffic data from 1986 was not available in its raw form, therefore only processed results were utilised in this paper.

\section{Roosboom, South Africa}

A recorded sample from the Roosboom WIM station on the N3 toll route between Durban and Johannesburg will serve as a preliminary data set for the comparison between the traffic in Auxerre and South Africa. Roosboom was chosen, because the N3 is the primary road freight corridor between Durban and Gauteng, and is therefore relevant to this study owing to high volumes of heavily loaded trucks. The Roosboom site is installed in a good-quality concrete pavement. The N3 has four lanes, two in each direction, but only the slow lanes are instrumented with WIM technology and are used for the evaluation.

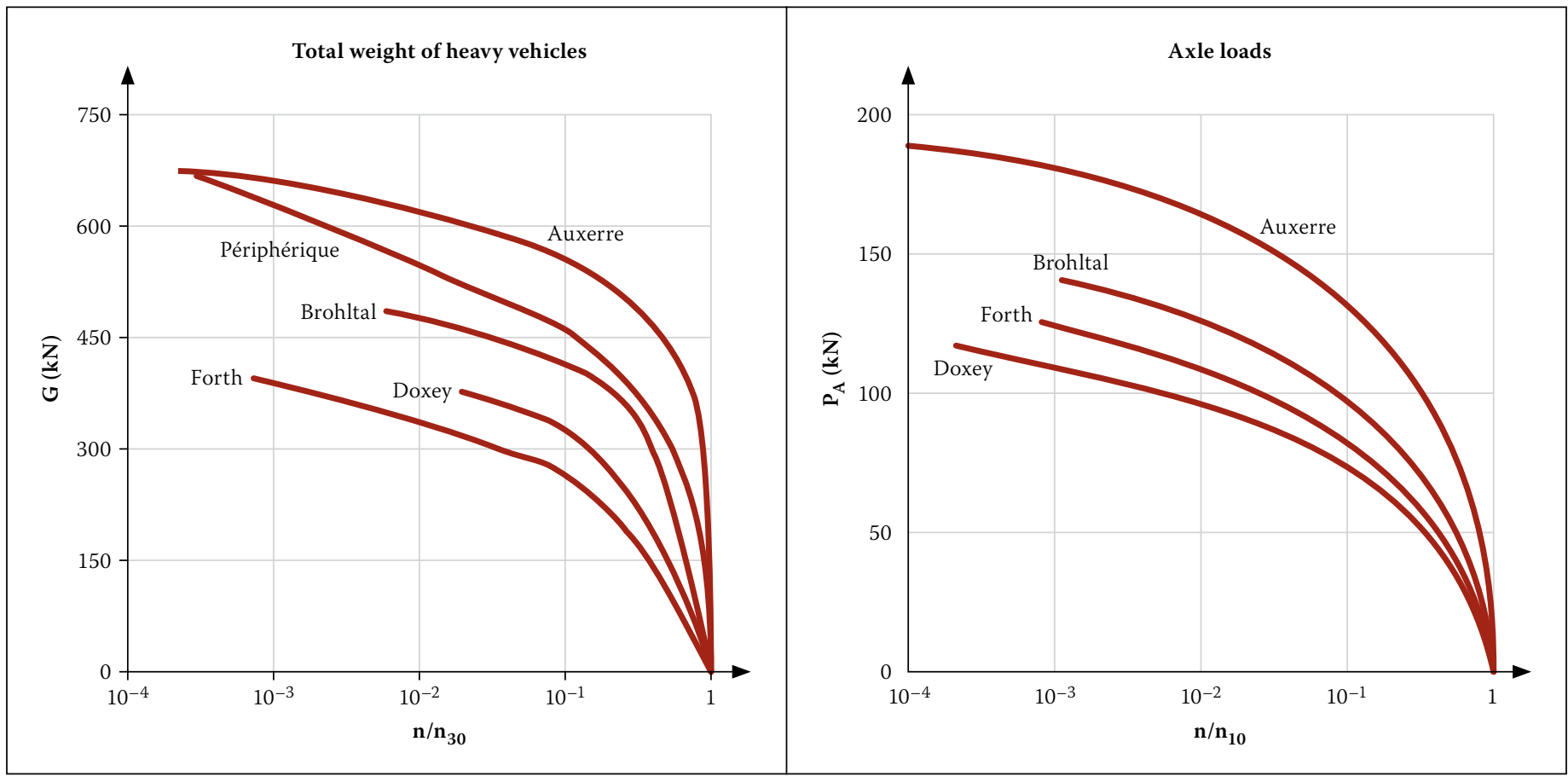

Figure 4: Gross vehicle and axle weight distribution of recorded traffic data from England, France and Germany (Hanswille \& Sedlacek 2007) 
The Roosboom site has been operational for about 14 years, and an extensive database of axle loading readings is therefore available. The chosen data sample for this evaluation was from August 2015, providing information about more than 74000 and 69000 vehicles in the northbound and southbound lanes respectively for a period of one month. The site uses bending plate sensors combined with electromagnetic inductive loops to collect traffic and axle loading data.

The site shows an Average Daily Truck Traffic (ADTT) of approximately $5100 \mathrm{veh} /$ day. The rigorous data quality checks that are performed on a routine basis using the Truck Tractor Method (De Wet \& Slavik 2013) confirmed that the site was well calibrated and that data quality was acceptable. Direct comparison of data quality to that from Auxerre is not possible. South African data quality assessment methods are, however, well aligned with international practice in leading countries such as the USA (Papagiannakis et al 2008; De Wet 2012) and, considering the improvement in WIM equipment and quality assurance over the past 30 years, it is argued that the Roosboom data is at least as good, but likely better, than the sample from Auxerre.

The data is represented in the RSA-2 format, a national standard (Schildhauer 2006). The RSA data format provides traffic count data for all vehicles, typically summarised in 15-minute recording intervals to reduce the file size, and for WIM stations it also contains individual heavy vehicle records showing, among other things, the axle loads and spacing. A new version of the data format, TMH-14, that will include individual vehicle records for all (light and heavy) vehicles has since been developed (COTO 2013) and will be rolled out to stations like Roosboom in due course.

It is important to note that, while WIM technology is used to estimate static loads, the WIM-measured data contains a dynamic component. The estimation of static weight is optimised by using good-quality WIM technology installed in pavements with suitable stiffness and riding quality, and utmost care is taken to install bending plates as flush with the road surface as possible.

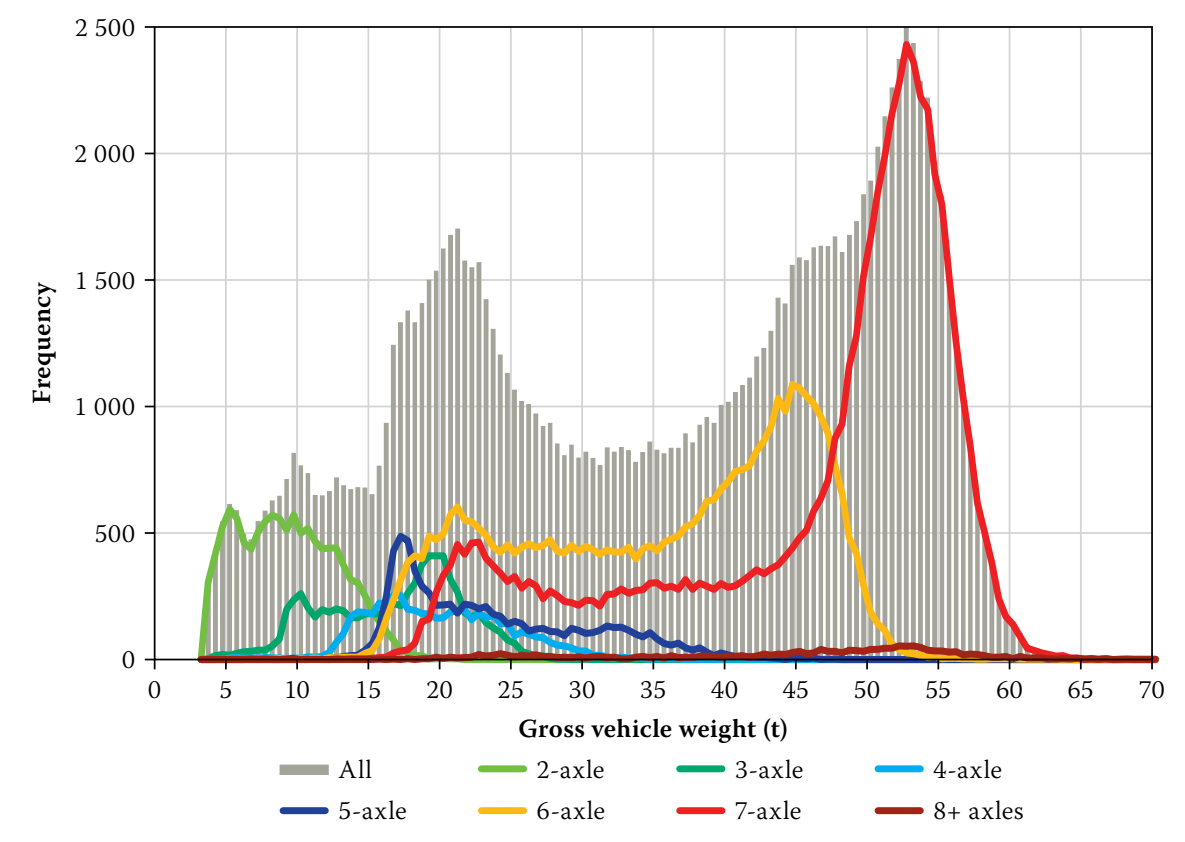

Figure 5: GVW distribution per vehicle type for the Roosboom data sample

Notwithstanding these efforts, loading distributions from WIM data will always be more dispersed than the true static distributions, owing to dynamic effects.

The composition of heavy vehicle traffic depends on overloading legislation and the freight route character of a road. The N3 Toll Road has a strong freight character since it connects Gauteng to Durban, and its port in particular. The majority of heavy vehicles travel the full length of the route, and 6- and 7 -axle trucks made up $73 \%$ of the trucks in the Roosboom WIM sample, because of their superior efficiency for long-distance freight. These vehicles are often loaded over the legal limit, but still within the grace that is allowed before they can be prosecuted. The South African Road Traffic Act, 1996 (Act No 93 of 1996), and the Road Traffic Regulations allow $2 \%$ grace before prosecution on exceedance of maximum permissible gross combination mass and bridge formula transgressions. The bridge formula relates the permissible mass to the distance $L$ in metres from the first axle of any axle unit to the last axle of any consecutive axle unit. A 5\% grace before prosecution is allowed on other overloading criteria. The most important overloading limits in South Africa are summarised in Table 1.

Table 1: Maximum permissible mass (kg) for heavy vehicles in South Africa

\begin{tabular}{|l|c|c|}
\hline \multicolumn{1}{|c|}{ Description } & Before 1 March 1996 & After March 1996 \\
\hline Single axle with 4 wheels & 8200 & 9000 \\
\hline Tandem axle unit (4 wheels/axle) & 16400 & 18000 \\
\hline Tridem axle unit (2 or 4 wheels/axle) & 21000 & 24000 \\
\hline Maximum combination mass & None & 56000 \\
\hline Bridge formula & $2100(\mathrm{~L})+15000$ & $2100(\mathrm{~L})+18000$ \\
\hline
\end{tabular}

Table 1 shows that a major change was made to South African overloading legislation in 1996, and overloading limits in Europe also changed over the past 30 years. In most European countries, the current maximum permissible GVW is generally restricted to only 40 tons, with legal limits on axle units similar to South Africa, but heavier unit loads are allowed on steering and driving axles with road-friendly suspensions. The result is a significant difference in heavy-vehicle composition between these countries. Whilst 6- and 7-axle vehicles dominate on South African freight routes, they are rarely found in Europe. The typical long-distance freight vehicle in Europe is a 5-axle articulated truck (2-axle tractor with a tridem axle semitrailer) (ACEA 2015).

The bridge loads in South Africa are therefore different from those in Europe. This is a clear contradiction to the observed results from Figure 2, where the LM1 results in significantly higher internal forces. It is therefore necessary to look at the traffic composition and parameters, like gross vehicle weight or axle loads, in detail.

The GVW distribution of the Roosboom samples seemingly follows a bi-modal normal distribution (see Figure 5), which is mainly due to the presence of various vehicle types (both loaded and unloaded). The mean value of the second peak is at approximately 53 tons. SANRAL uses a vehicle classification system (Smith \& Visser 2008), and the SANRAL Class 16 vehicles, consisting of 7-axle multi-trailer vehicles, represent the predominant loading at this site. The following sections provide more detail on the makeup of the total traffic. 
Table 2: Simplification of classification scheme for comparison purposes

\begin{tabular}{|c|c|c|}
\hline Type & SANRAL code & SANRAL description \\
\hline 1 & 5 & Two-axle single unit \\
\hline 2 & 8 & Three-axle single unit \\
\hline 3 & $9,12,13$ & Multi-axle single trailer \\
\hline 4 & $14,15,16,17$ & Multi-axle multi-trailer \\
\hline
\end{tabular}

\section{COMPARISON OF TRAFFIC DATA}

The data from the N3 was first categorised to fit the same format as in (Sedlacek et al 2008; Hanswille \& Sedlacek 2007) to allow for a sensible comparison. The SANRAL classification scheme provides 17 different classes (COTO 2013), while the Auxerre traffic is divided into four different types. Type 1 is a double-axle vehicle, Type 2 covers rigid vehicles with more than two axles, Type 3 is articulated vehicles and Type 4 is drawbar vehicles. The distribution in
Table 2 (of SANRAL classes into the four different types) is utilised throughout this document.

\section{Gross vehicle weight}

It is interesting to look at the traffic composition and the frequency distribution of each Figure 6 shows the percentage of the total truck traffic that is made up by each type of vehicle. It is apparent that Type 3 is prevalent for the Auxerre data sample, while the data vehicle type, especially heavy-load vehicles.

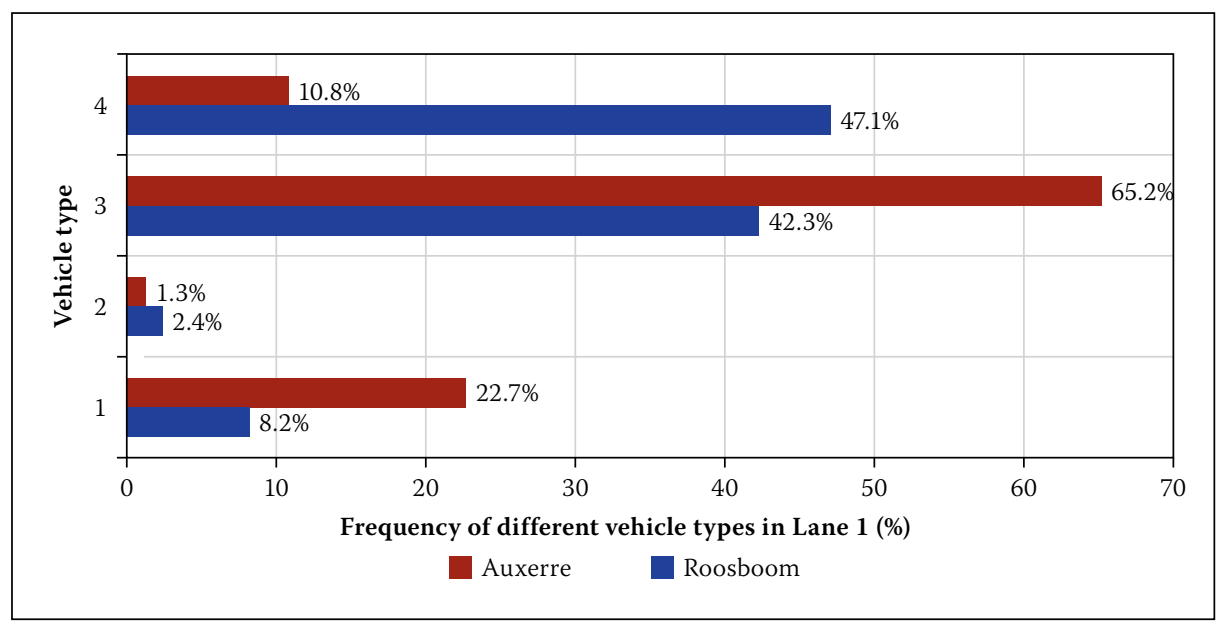

Figure 6: Frequency of the different vehicle types in Lane 1 from Roosboom shows a high percentage of Type 3 and Type 4 vehicles. While Auxerre already exhibited a large percentage of long heavy trucks, there is indication of possibly even heavier traffic density on South African roads. This is the result of South African legislation allowing vehicles to be loaded up to $56 \mathrm{t}$, while European trucks are generally restricted to $40 \mathrm{t}$.

Figure 7 exhibits the calculated gross vehicle weight GVW $>30 \mathrm{kN}$ and axle load $\mathrm{P}_{\mathrm{A}}>10 \mathrm{kN}$ frequency distributions of the Roosboom sample transposed over the frequencies from (Hanswille \& Sedlacek 2007), shown in Figure 4. Overall, it seems like the heavy traffic intensity at Roosboom is quite similar to Auxerre, with the exception of heavier GVW at very small frequencies, possibly a result of overloading. The GVW is consistently larger when compared to other European data. The observed axle loads at Roosboom, on the other hand, are significantly smaller when compared to Auxerre, and in the similar range when compared to the other stations.

Further comparisons according to the specified vehicle types are shown in Figure 8. A representative sample of vehicles per 24 hours was used by (Hanswille \& Sedlacek 2007). To allow comparison, a 24-hour data sample from Roosboom on 4 August 2015 was used as a representative of daily traffic. Full month data was also checked in order to make sure that there are no significant deviations. As a result, the frequency distribution for daily and monthly traffic is very similar, with the exception of some outlying very heavy vehicles present in the data representing the full month.

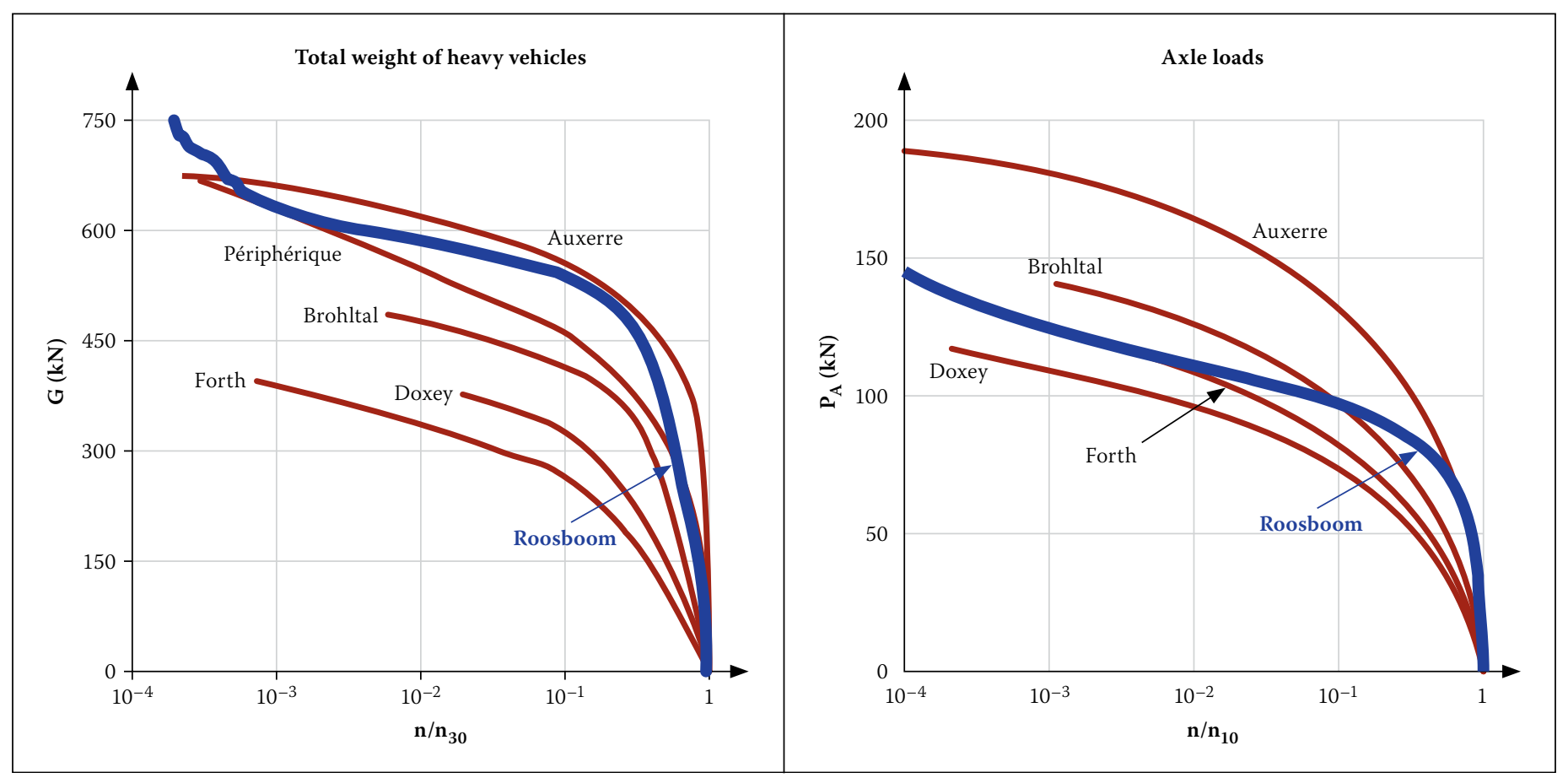

Figure 7: Gross vehicle weight and axle weight distribution of recorded traffic data 

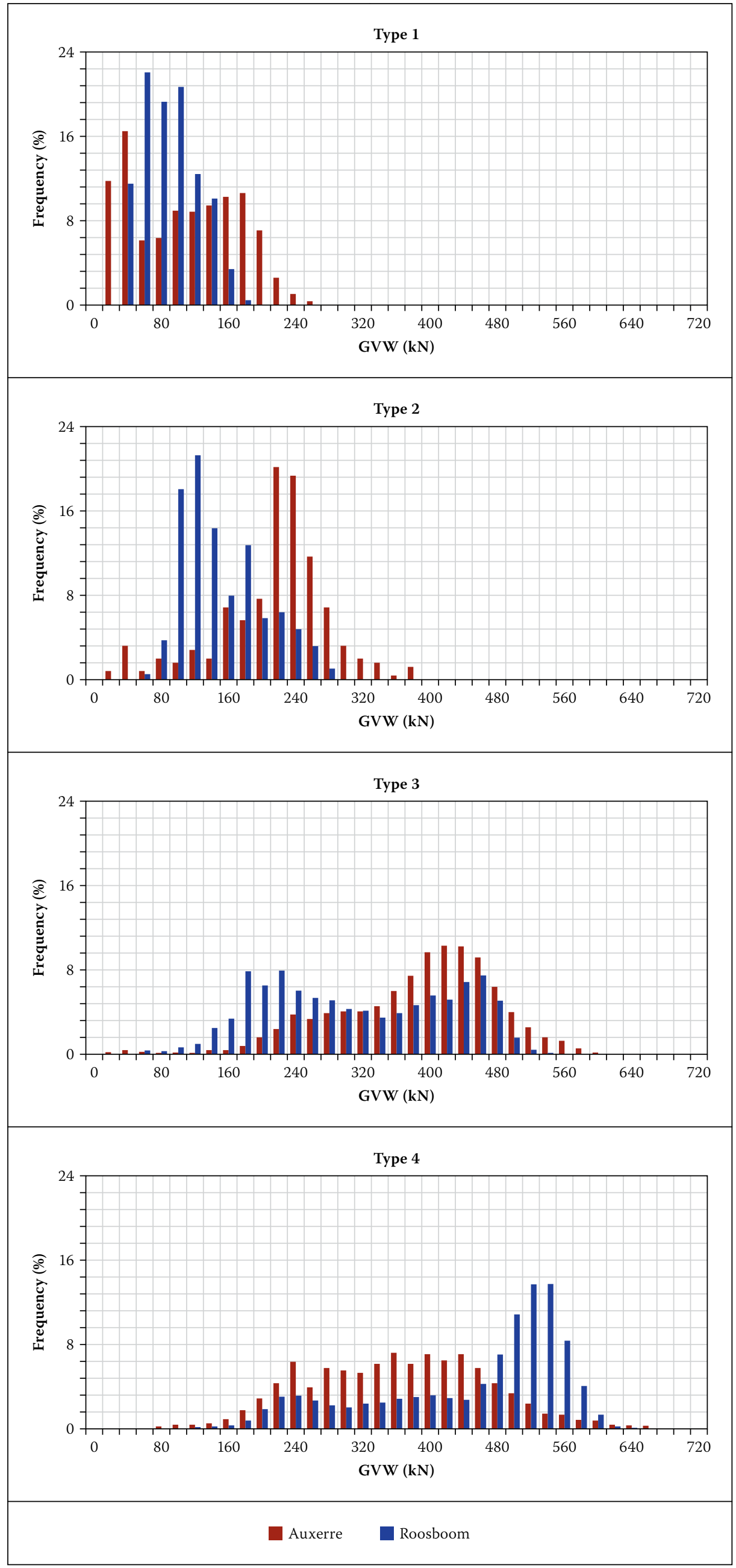

Figure 8: Weight gross vehicle distributions for Auxerre and Roosboom in kN
The most important observation from Figure 8 is the higher number of loaded Type 4 vehicles at N3 Roosboom compared to Auxerre, with the picture for Type 3 trucks swapped around. The key reason is that Type 3 trucks are the most efficient heavyfreight vehicles within the European legislative context (and therefore dominate the scene in terms of utilisation and loading efficiency), while Type 4 trucks fulfil this role in South Africa. Auxerre traffic apparently exhibits a higher number of heavier vehicles for Types 1 and 2, possibly because of greater loading allowances on road-friendly suspensions.

\section{Axle loads at Roosboom}

It is not only the GVW frequency distribution, but also the frequency distribution of the axle loads, that needs consideration for the development of a bridge loading model. Generally the frequency distribution of axle loads exhibits, similar to GVW, two distinct peaks relating to the unloaded and loaded axles. The properties of loaded axles are of interest. A comparison of axle load frequencies for the one-month Roosboom sample is shown in Figure 9 for both vehicle Types 3 and 4. Types 1 and 2 are omitted in this paper because they are light vehicles and comprise only approximately $15 \%$ of total N3 heavy traffic. The first axle carrying the engine is essentially always loaded and the heavier engines for the higher powered 7-axle trucks are evident. The first axle also has a lower permissible legal allowance (7.7 tons) than the other axles. The rest of the axles generally exhibit the two distinctive peaks, which is especially apparent for Type 4 vehicles. These vehicles tend to be efficiently loaded in both directions, and the axle distribution also tends to be more stable, while there is a clear indication of less effective loading of Type 3 vehicles. The heaviest load may, however, be observed on Type 3 - Axle 2. The distribution is in line with the fact that the permissible load on the driving double axles (Axles 2 and 3 ) is 9 tons per axle, while the maximum permissible load for the trailer triple axles is only 8 tons per axle.

Typically, a distribution function is fitted to the data in order to characterise the random variables representing the loaded axle load. In this case, normal distributions were fitted to the loaded axle by engineering judgement, as can be seen in Figure 10. It is important to note that mean value and standard deviation are of particular interest regarding the fitting. Normal distribution is observed for axle loads in general (Bogath \& Bergmeister 1997).

Table 3 and Figure 11 show the mean values and standard deviations of axle loads in $\mathrm{kN}$ for the various axles of vehicle Types 3 


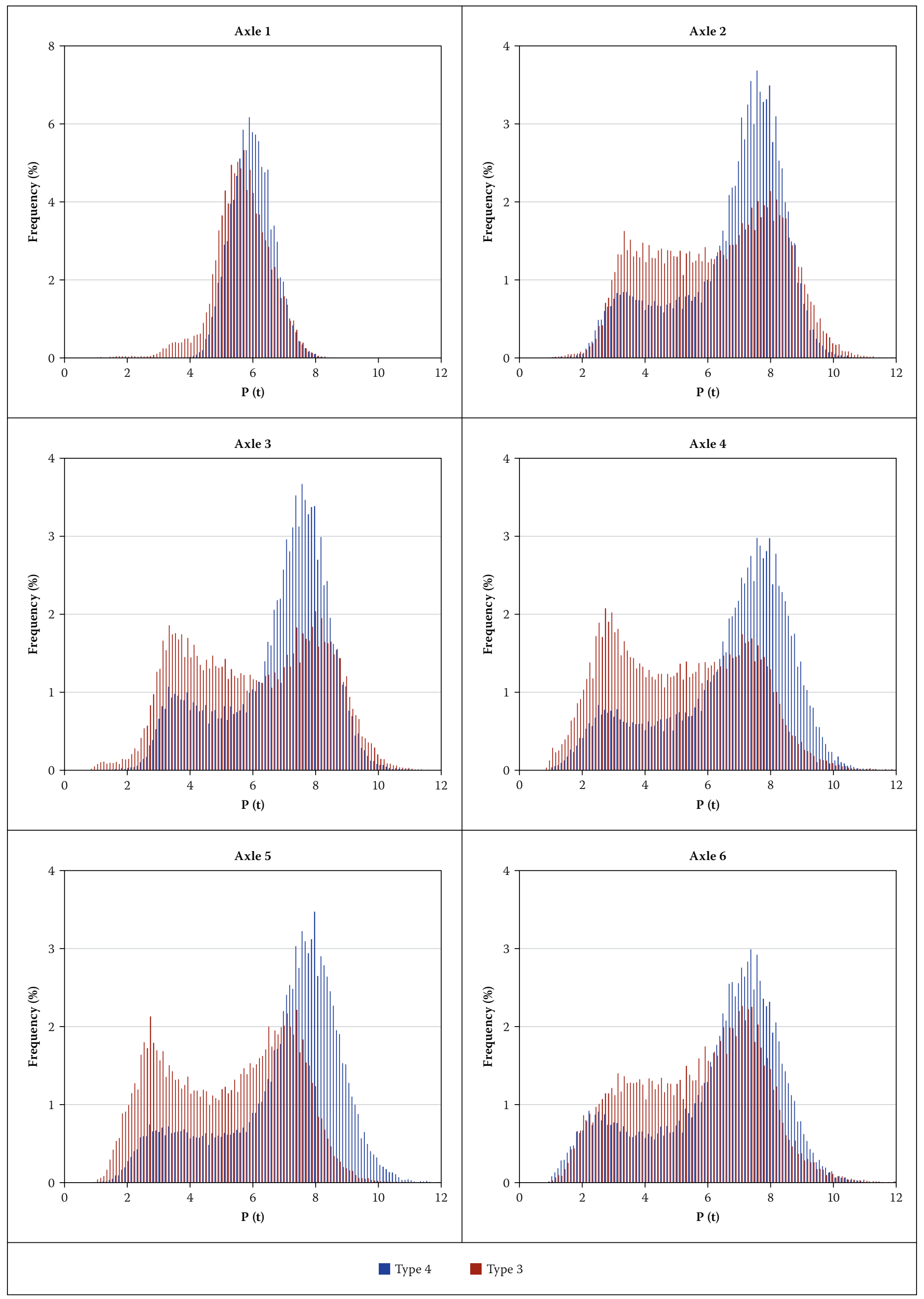

Figure 9: Axle load frequencies of Type 3 and Type 4 vehicles, Roosboom WIM 


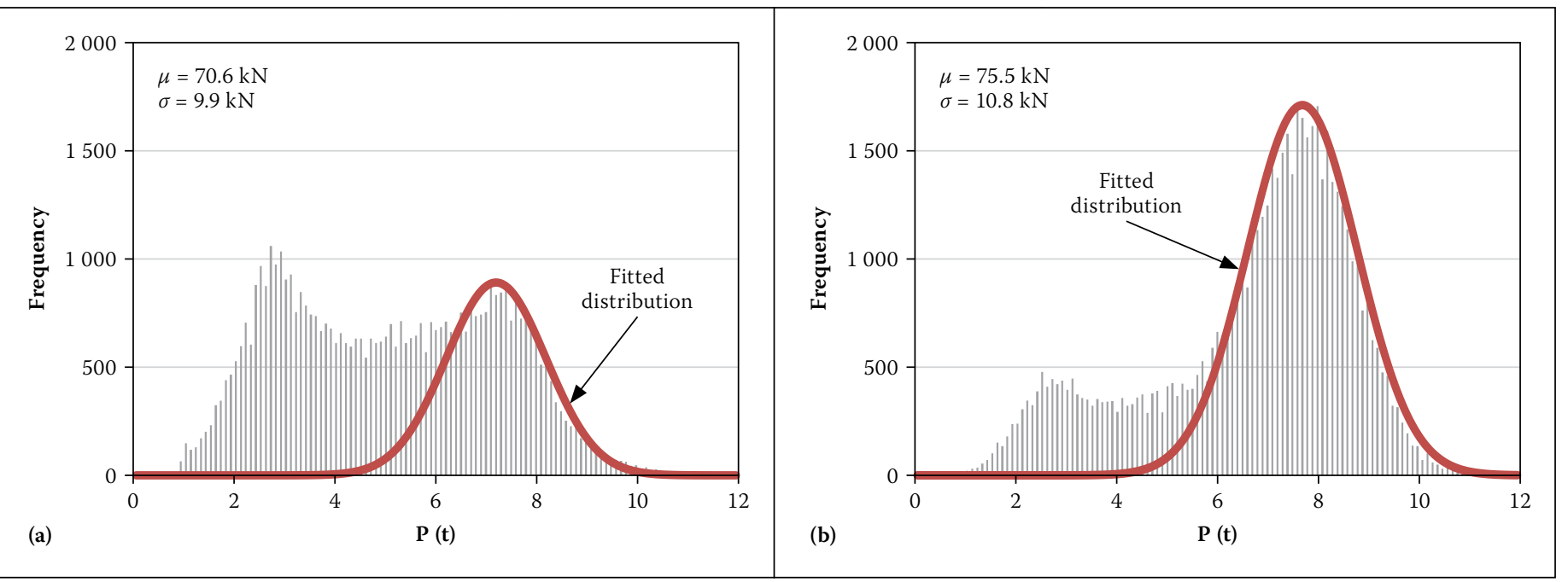

Figure 10: Fitted normal distribution to axle load frequency - (a) Type 3 axle 4 and (b) Type 4 axle 4 vehicles

and 4, as compared to the data available for Auxerre traffic. Similar mean values are provided by Bosman (2008), thus validating the results obtained here.

As can be seen in Table 3, the data provided for Auxerre traffic has a maximum number of five axles, while Roosboom has recorded seven axles. Nevertheless, the maximum mean value is recorded for Axle 2 of Auxerre traffic. It is also very interesting to observe the mean values of the Roosboom sample, where all of the axles (besides front) tend to be in the range of $70-80 \mathrm{kN}$. This again highlights the fact that the total weight of the vehicles is larger in comparison to Auxerre, even though axle loads observed at Auxerre, especially Axle 2, exhibit larger mean values. Another very important observation is the value of standard deviation which largely influences the statistical extrapolation of axle loads. The larger the standard deviation is, the larger the extreme value that can be expected. It is clear that Roosboom data has comparatively smaller standard deviation, along with smaller mean value. This is an indication that lower extrapolated values can be expected for axle loads.

The axle spacing measured at Roosboom (shown in Table 4 and Figure 12) is difficult to compare to values on record for Auxerre, due to the different classes of vehicles. However, the most important parameter, namely the spacing at the tandem axle, seems to be comparable, and the value of $1.2 \mathrm{~m}$ specified for LM1 could be relevant in South Africa, since the research showed that the spacing between driving doubleaxles on truck tractors in South Africa is

Table 3: Axle loads in kN - normal distributions

\begin{tabular}{|c|c|c|c|c|c|c|c|c|c|c|c|c|c|c|c|}
\hline \multirow{2}{*}{ Type } & \multirow{2}{*}{ Station } & \multicolumn{2}{|c|}{ Axle 1} & \multicolumn{2}{|c|}{ Axle 2} & \multicolumn{2}{|c|}{ Axle 3} & \multicolumn{2}{|c|}{ Axle 4} & \multicolumn{2}{|c|}{ Axle 5} & \multicolumn{2}{|c|}{ Axle 6} & \multicolumn{2}{|c|}{ Axle 7} \\
\hline & & $\mu$ & $\sigma$ & $\mu$ & $\sigma$ & $\mu$ & $\sigma$ & $\mu$ & $\sigma$ & $\mu$ & $\sigma$ & $\mu$ & $\sigma$ & $\mu$ & $\sigma$ \\
\hline \multirow{2}{*}{ T3 } & Auxerre & 79.2 & 11.1 & 124.5 & 20.4 & 92.1 & 13.9 & 88.0 & 13.0 & 77.3 & 15.6 & - & - & - & - \\
\hline & Roosboom & 55.4 & 8.1 & 79.2 & 10.5 & 78.5 & 9.8 & 70.6 & 9.9 & 68.7 & 8.8 & 69.7 & 10.3 & - & - \\
\hline \multirow{2}{*}{$\mathrm{T} 4$} & Auxerre & 82.0 & 18.1 & 128.9 & 18.6 & 83.7 & 15.9 & 81.1 & 15.1 & 67.3 & 19.0 & - & - & - & - \\
\hline & Roosboom & 58.9 & 6.9 & 75.0 & 8.3 & 74.9 & 8.8 & 75.5 & 10.8 & 77.0 & 9.6 & 72.1 & 9.8 & 71.6 & 10.1 \\
\hline
\end{tabular}

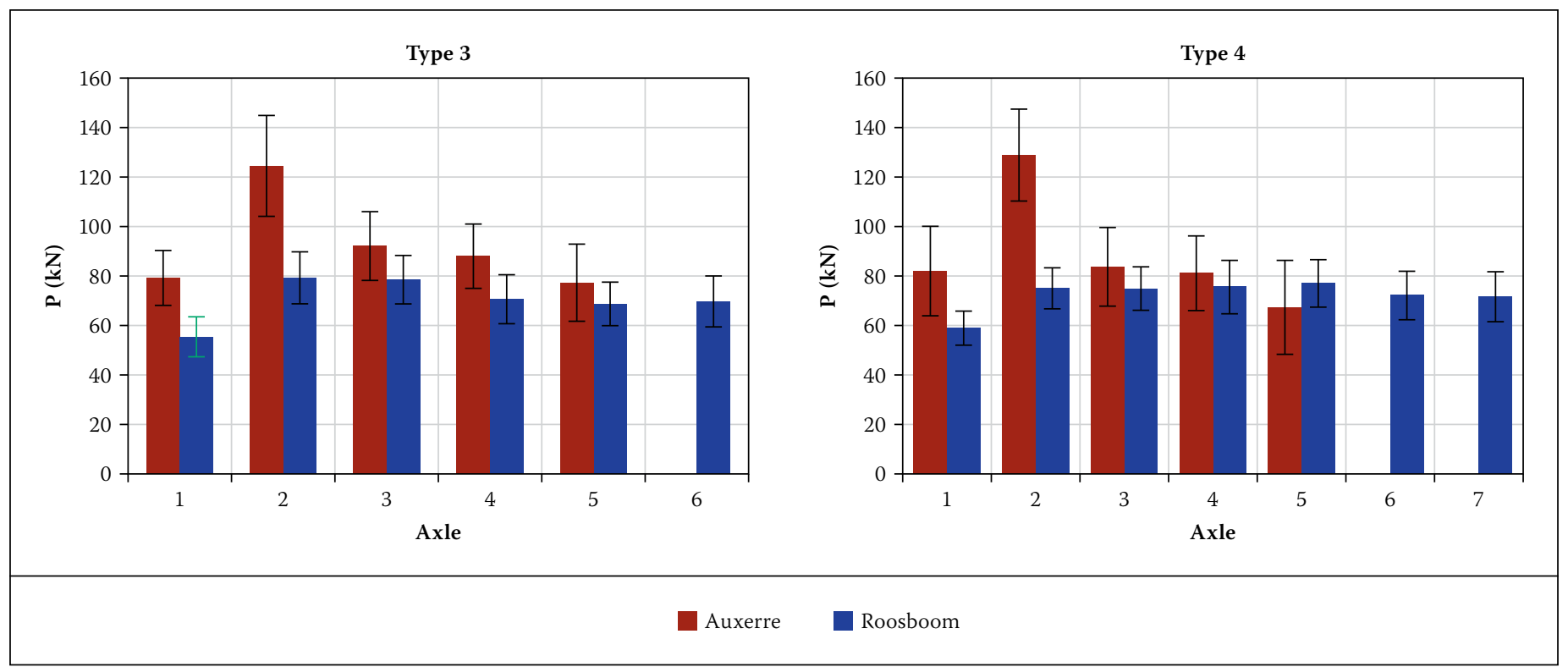

Figure 11: Graphical representation of mean axle loads and associated standard deviation - Type 3 and Type 4 vehicles 
Table 4: Axle spacing - normal distribution

\begin{tabular}{|c|c|c|c|c|c|c|c|c|c|c|c|c|c|}
\hline \multirow{2}{*}{ Type } & \multirow{2}{*}{ Station } & \multicolumn{2}{|c|}{ Axle 1-2 } & \multicolumn{2}{|c|}{ Axle 2-3 } & \multicolumn{2}{|c|}{ Axle 3-4 } & \multicolumn{2}{|c|}{ Axle 4-5 } & \multicolumn{2}{|c|}{ Axle 5-6 } & \multicolumn{2}{|c|}{ Axle 6-7 } \\
\hline & & $\mu$ & $\sigma$ & $\mu$ & $\sigma$ & $\mu$ & $\sigma$ & $\mu$ & $\sigma$ & $\mu$ & $\sigma$ & $\mu$ & $\sigma$ \\
\hline \multirow{2}{*}{ T3 } & Auxerre & 3.30 & 0.26 & 4.71 & 0.78 & 1.22 & 0.13 & 1.23 & 0.14 & - & - & - & - \\
\hline & Roosboom & 3.48 & 0.87 & 2.22 & 2.24 & 6.63 & 2.02 & 1.41 & 0.58 & 1.34 & 0.06 & - & - \\
\hline \multirow{2}{*}{$\mathrm{T} 4$} & Auxerre & 4.27 & 0.40 & 4.12 & 0.31 & 4.00 & 0.42 & 1.25 & 0.03 & - & - & - & - \\
\hline & Roosboom & 3.26 & 0.83 & 1.48 & 0.85 & 5.86 & 1.15 & 1.51 & 0.98 & 5.48 & 1.35 & 1.46 & 0.60 \\
\hline
\end{tabular}

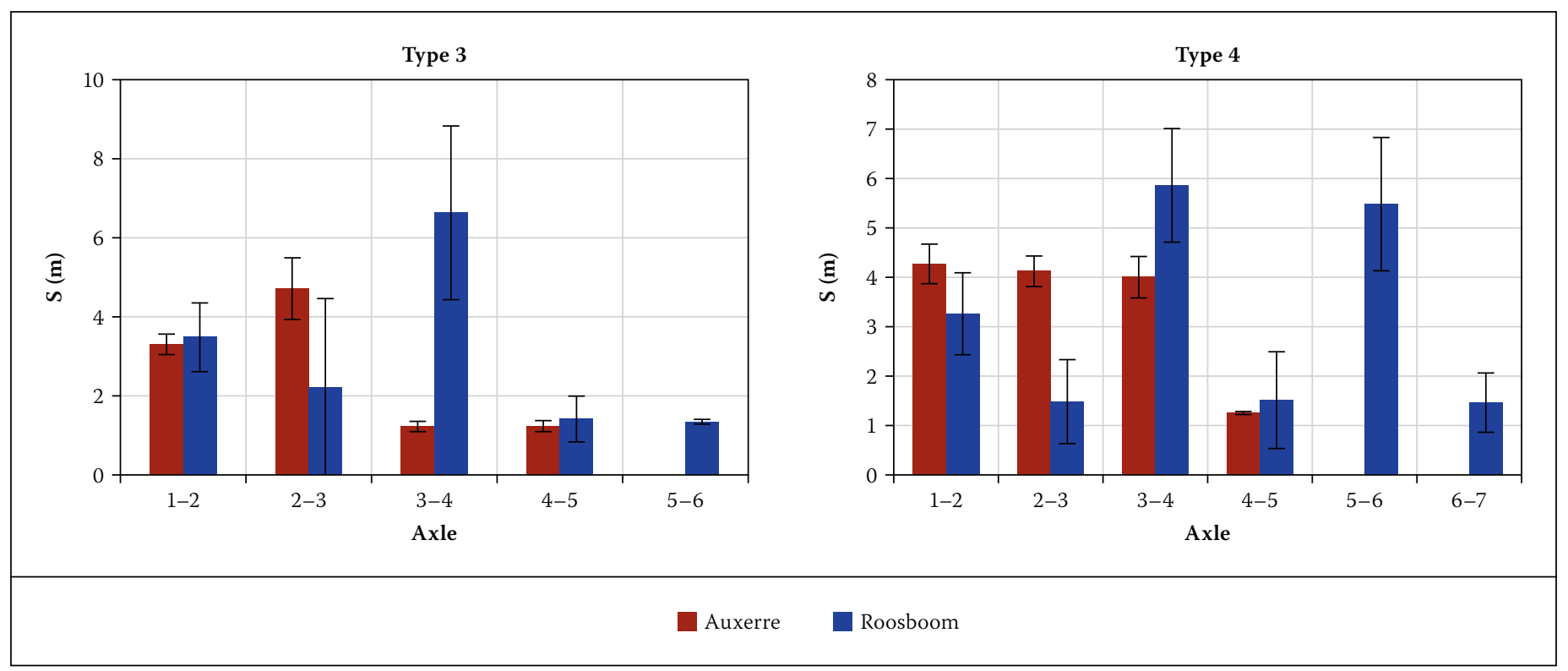

Figure 12: Graphical representation of mean axle spacing and associated standard deviation - Type 3 and Type 4 vehicles

approximately $1.35 \mathrm{~m}$, with a spread as small as $\pm 3 \%$ (Slavik \& De Wet 2012).

In light of the observations above, the loading model for South African highways is likely to have lower axle loads, but higher distributed loading, to compensate for the heavier vehicles and their large frequency. This, however, must be validated with further evaluation of WIM measurements, simulations of traffic loads on various influence lines representing various static systems and a proper investigation of dynamic amplification effects.

\section{GENERAL AXLE LOADING IN SOUTH AFRICA}

In order to develop a suitable bridge loading model, a wide range of data is necessary in order to sufficiently describe the statistical parameters of load axles observed on South African roads. It is more prudent to use data from more than a single source to obtain a representative figure. The frequency distribution is a key parameter in derivation of a bridge load model.

Mechanistic pavement design methods rely on axle load distributions to optimise the design of pavement layers. This detailed axle loading information is often not available, and methods have been derived
(Slavik 2013) to estimate the loading characteristics of a particular road based on available traffic counts. As a result a method called ALDIS was developed by Slavik (2013) to estimate axle load distributions. The ALDIS methodology was also incorporated into a spreadsheet model called MOLD (Modelling of Load Distributions). This method is used to illustrate the variability of axle loading on different routes.

The method was developed using a stratified selection of 22 weigh-in-motion stations on South African freight routes and relies on three input parameters to estimate the axle load distribution:

- Intensity of overloading law enforcement (strong, some or none)

- Freight route category (ranging from A, export routes with most trucks fully loaded to D, routes with mostly lightly loaded trucks)

- Heavy vehicle composition (split into short, medium and long heavy vehicles). Figure 13 shows a screenshot from MOLD of the axle load distribution for Roosboom, using the actual vehicle classification from loop counts, 'some' law enforcement and the freight route category defined as Category B.

Figure 14 shows how the actual WIMmeasured axle load distributions for Roosboom northbound and southbound compared to default distributions for freight route categories A to D. It is evident that axle load distributions on freight routes can be vastly different. Roosboom axle load frequencies correspond closely to Category B. The shape of Category A also shows that worse loading examples than Roosboom have been recorded on South African National Routes. At the same time, the Roosboom southbound seems to closely follow the end tail for Category A.

Due to the aggregate nature of the data, it should be noted that the axle load does not necessarily follow a normal distribution, yet the distribution may be used in determination of the vertical characteristic load on bridges due to traffic.

\section{Characteristic load}

Generally, a traffic loading model is developed on the basis of numerical simulations. Artificial traffic realisations are generated based on distributions fitted to the real traffic measurements. Alternatively, distributions from MOLD may be utilised in order to study more generalised traffic. Subsequently, the generated artificial traffic flow serves as the basis for calculation of load effects on a bridge structure due to vehicular loads. This results in a set of observed data. The maxima distribution in 


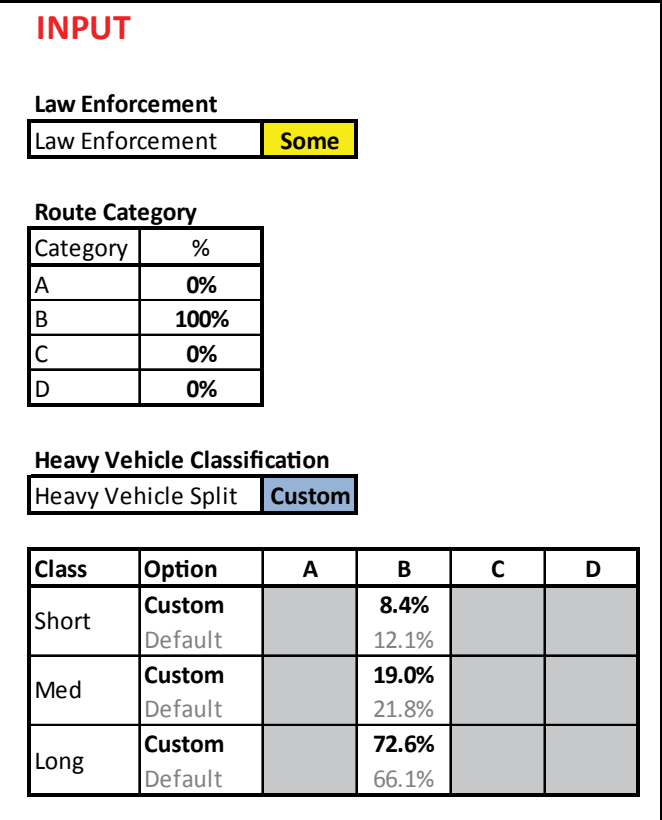

\section{OUTPUT}

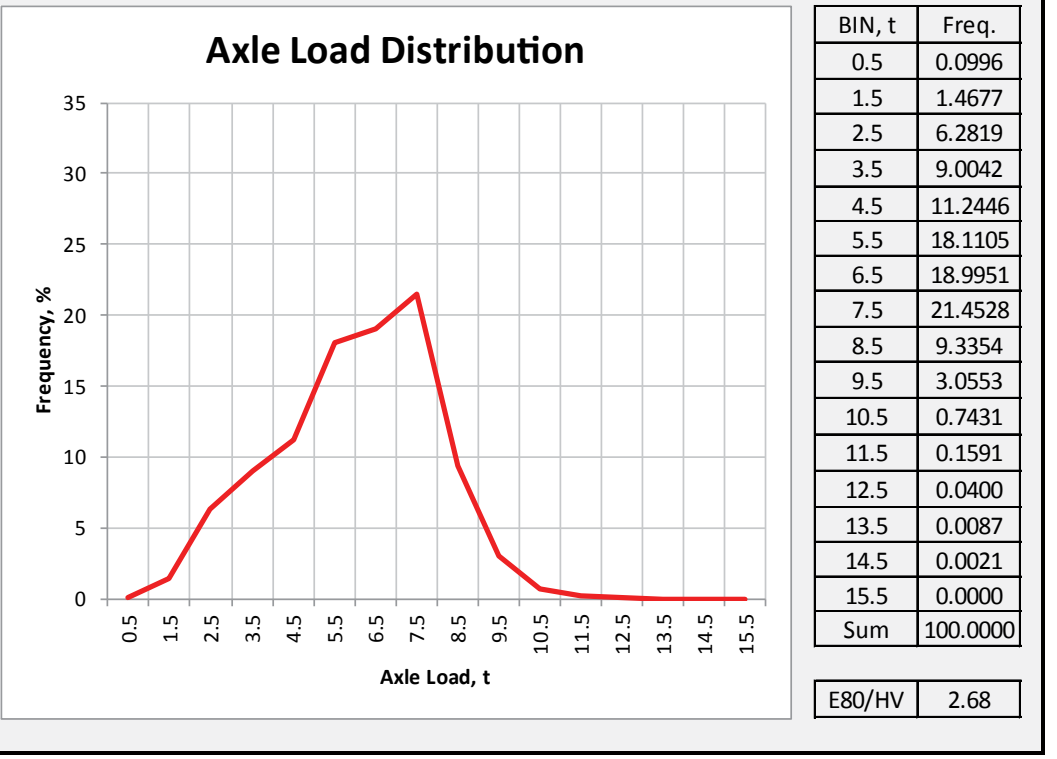

Figure 13: MOLD axle load distribution, freight route Category B

a specified period $\mathrm{F}_{n}(x)$ is simply obtained according to Equation 2:

$\mathrm{F}_{n}(x)=\mathrm{F}(x)^{n}$

where $n$ is related to the number of vehicles in the required return period and $\mathrm{F}(x)$ is a distribution of observed internal force.

This approach may, however, lead to large discrepancies of maxima when even small discrepancies of observed data are present (Coles 1991). It is therefore more appropriate to utilise asymptotic models and estimate approximate distributions based on the extreme data only, which in this case may be daily maxima of observed internal forces. A simplified approach for a single vehicle in the local context was shown to provide a basis for further calibration (Anderson 2006). The thorough statistical extrapolation of all load effects considering multiple vehicles and multiple lanes is out of the scope of this paper, but it should be mentioned that the input parameters for the generation of artificial traffic should be tied to the MOLD model. This would allow for investigation of the influence of parameters such as road category and law enforcement on the characteristic load. It would therefore make it possible to study these parameters, perform sensitivity analysis and develop a robust solution for the loading model. As an example, the law enforcement parameter is shown here in detail. The tail-end distribution variation and mean value shift according to the level of law enforcement can

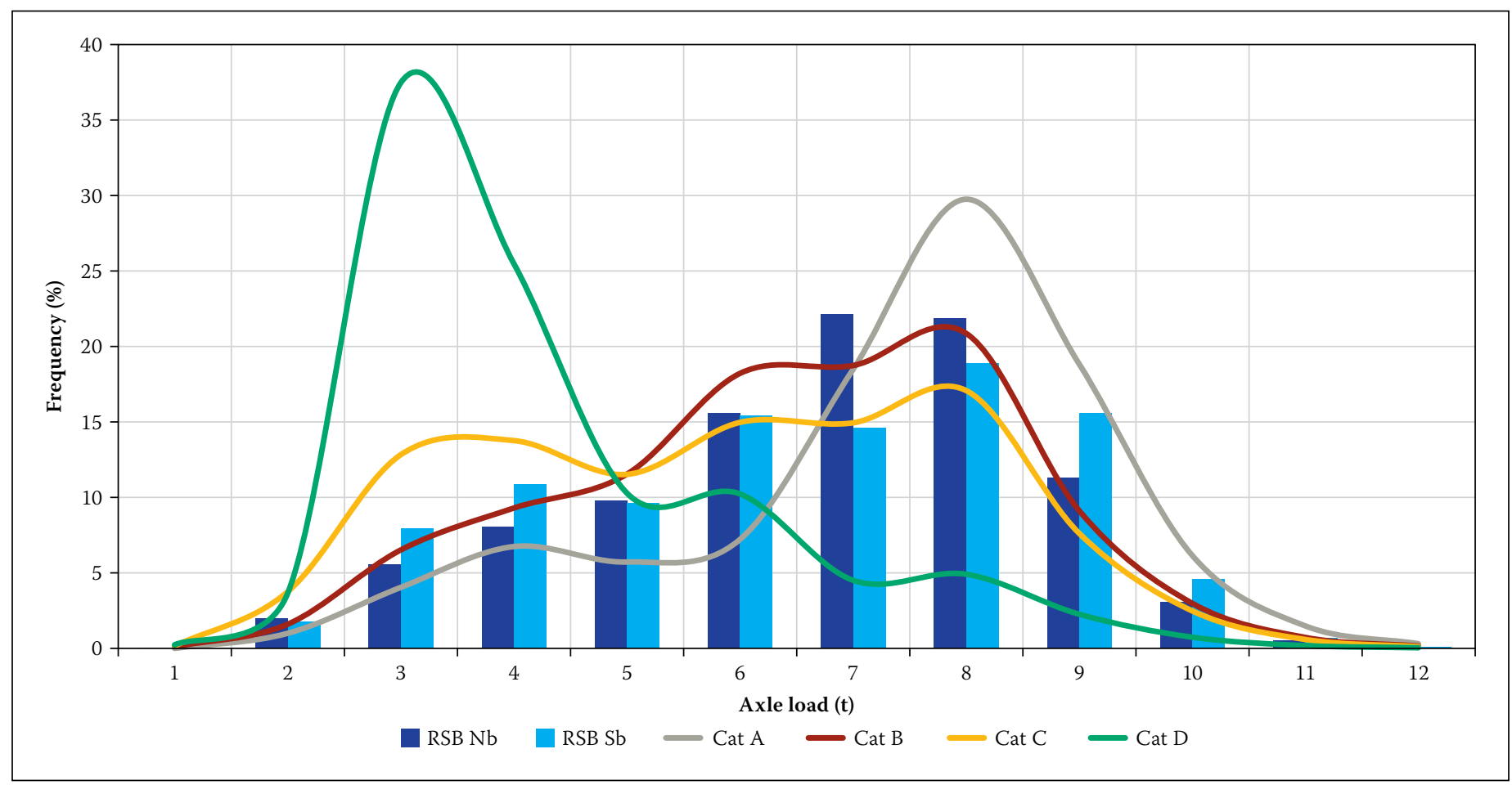

Figure 14: Roosboom axle load distributions, compared to MOLD Categories A-D 


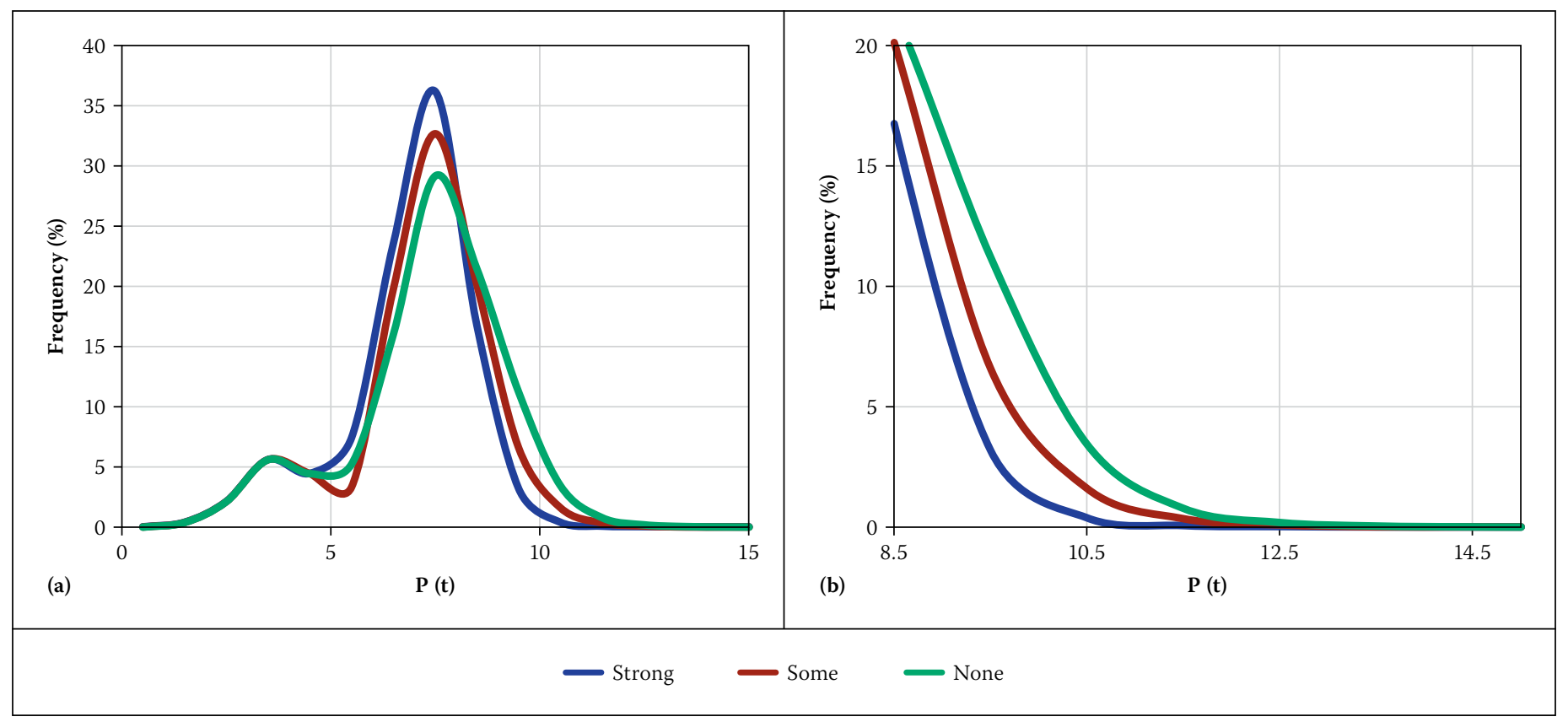

Figure 15: Frequency distribution of axle loads of Category A with variable law enforcement - (a) shift of mean value, and (b) tail-end distribution

be observed in Figure 15. A change in axle load distribution, especially of the tail-end, will certainly influence the characteristic load. Further detailed study is absolutely necessary, along with proper extrapolation of results to the specified return period or bridge design lifetime.

\section{CONCLUSIONS}

SAICE (2008) recognised the need for revising the TMH-7 load model (CSRA 1981). A single model for both global and local verification is desirable. It is, however, clear from the presented results that a simple adoption of LM1 from EN 1991-2 (EN 2010) is not possible, due to a number of reasons.

LM1 loading generally provides higher internal forces when compared to TMH-7 loading, with lower values found only at lane width discrepancies. This implies that a direct adoption of current LM1 loading would result in more expensive bridge structures across South Africa, without substantiation, considering the satisfactory past performance of existing structures.

The gross vehicle weights (GVW) observed in South Africa are, however, even higher than the vehicular loads considered during the development of LM1. This implies that the current TMH-7 NA distributed loading may be too low and may provide an insufficient safety margin, given the actual load conditions faced by South African bridges.

Axle loads on the N3 highway in South Africa are lower in comparison to data from 1986 Auxerre, France. The extrapolated characteristic axle loads are likely to be lower as well, due to the reduced standard deviation. Further data from additional routes are, however, necessary. Although localised load effects were not considered in this paper, it may be assumed that they are less of a concern when revising the TMH-7 loading.

In order to remediate the current situation, it is recommended to develop or adapt a loading model that simplifies the existing unnecessarily cumbersome provisions. The model should in the interim be calibrated to the current TMH-7 loading levels. This may be problematic due to clearly high levels of ADTT and high GVW, but can be justified for the interim, given the past satisfactory performance of South African bridges. Further studies of axle load frequency accounting for parameters such as route category and law enforcement are necessary in order to develop a new model. It is pertinent to develop representative axle loads and perform numerical simulations, along with statistical extrapolation of internal forces, in order to establish a loading model that reflects the current traffic and associated loading levels while providing sufficient safety margin and economical construction.

\section{ACKNOWLEDGEMENTS}

The authors would like to acknowledge N3 Toll Concession for the use of WIM data, and Subcommittee B of the Research Committee at Stellenbosch University for financial support. Comments and suggestions provided by the reviewers are appreciated.

\section{REFERENCES}

ACEA (European Automobile Manufacturers'

Association) 2015. Heavy-duty Vehicle Weight

Restrictions in the EU - Enforcement and

Compliance Technologies. Ljubljana, Slovenia: ZAG.
Anderson, J 2006. Review of South African live load models for traffic loading on bridge and culvert structures using Weigh-in-Motion (WIM) data. MSc Dissertation, University of Cape Town.

Bogath, J \& Bergmeister, K 1997. Neues Lastmodell für Straßenbrücken. Bauingenieur, 74(6): 271-277.

Bosman, J 2008. Traffic loading characteristics of South African heavy vehicles. Proceedings, 8th International Symposium on Heavy Vehicle Weights and Dimensions, 14-18 March, Johannesburg.

EN (European Standard) 2010. EN 1991-22010. Actions on Structures. Part 2: Traffic Loading on Bridges. Brussels: European Committee for Standardization (CEN).

Coles, S 1991. An Introduction to Statistical Modeling of Extreme Values. London: Springer.

COTO (Committee of Transport Officials) 2013.

TMH 14. South African Standard Automatic Traffic Data Collection Format. Pretoria: SANRAL.

COTO (Committee of Transport Officials) 2014. TMH 8. Traffic and Axle Load Monitoring Procedures. Pretoria: SANRAL

COTO (Committee of Transport Officials) 2016. TMH 3 Specifications for the Provision of Traffic and Weigh-in-Motion Monitoring Service Draft 1.5. Pretoria: SANRAL.

COST 323 2002. Weigh-in-Motion of Road Vehicles: Final Report. Appendix I: European WIM Specification. Paris: COST/LCPC.

CSRA (Committee of State Road Authorities) 1981. TMH 7 Code of Practice for the Design of Highway Bridges and Culverts in South Africa. Part 2: Specification for Loads. Pretoria. Pretoria: CSRA, Department of Transport.

CSRA (Committee of State Road Authorities) 1991. TMH 7 Code of Practice for the Design of Highway Bridges and Culverts in South Africa. Part 2: Traffic Loading (1991) Proposed substitution of Section 2.6. Pretoria: CSRA, Department of Transport.

De Wet, D 2008. Revision of the South African Flexible Pavement Design Method. Correction of systematic error in WIM data, 3rd draft. Pretoria: SANRAL. 
De Wet, D 2010. Post-calibration and quality management of Weigh-in-Motion traffic data. MSc Dissertation, Stellenbosch University.

De Wet, D 2012. Data-based WIM calibration and data quality assessment in South Africa. Proceedings, 6th International Conference on Weigh-in-Motion, 4-7 June, Dallas, TX, 209-217.

De Wet, D \& Slavik, M 2013. Technical specification for traffic data collection for toll concessionaires. Pretoria: AECOM.

Hanswille, G \& Sedlacek, G 2007. Background report - Traffic loads on roads bridges: Basis of the load models in EN 1991-2 and DIN - Report 101, Draft.

Papagiannakis, A, Quinly, R \& Brandt, S 2008. NCHRP Synthesis 386 - High-speed Weigh-in-Motion system calibration practices. Washington, DC: Transportation Research Board.

SAICE 2008. Report on the Structural Eurocode Summit: 8 February. Pretoria: SAICE Joint Structural Division. SANS (South African National Standard) 2011. SANS 10160-1:2011. Basis of Structural Design and Actions for Buildings and Industrial Structures. Pretoria: SABS Standards Division.

Schildhauer, C 2006. South African standard traffic data collection format, Version 2.00, Issue 2006/05/05. Pretoria: SANRAL.

Sedlacek, G, Merzenich, G \& Paschen, M 2008. Background document to EN 1991- Part 2 - Traffic loads for road bridges - and consequences for the design. JRC Scientific and Technical Reports.
Slavik, M 2013. Axle-load estimation without Weighin-Motion survey. Proceedings, 32nd Southern African Transport Conference, 8-11 July, Pretoria, 128-137.

Slavik, M \& De Wet, D 2012. Checking WIM axle-spacing measurements. Proceedings, 6th International Conference on Weigh-in-Motion, 4-7 June, Dallas, TX.

Smith, A \& Visser, A 2008. A South African road network classification based on traffic loading. Proceedings, 8th International Symposium on Heavy Vehicle Weights and Dimensions, 14-18 March, Johannesburg. 